Pesq. Vet. Bras. 29(3):253-257, março 2009

\title{
Survey on control and management practices of equine helminthes infection ${ }^{1}$
}

\author{
Isabella V.F. Martins ${ }^{2 \star}$, Guilherme G. Verocai ${ }^{3}$ Thais R. Correia ${ }^{3}$, Raquel \\ M.P.S. Melo ${ }^{3}$, Maria Julia S. Pereira ${ }^{3}$, Fabio B. Scott ${ }^{3}$, and Laerte Grisi ${ }^{3}$
}

\begin{abstract}
Martins I.V.F., Verocai G.G., Correia T.R., Melo R.M.P.S., Pereira M.J.S., Scott F.B. \& Grisi L. 2009. Survey on control and management practices of equine helminths infection. Pesquisa Veterinária Brasileira 29(3):253-257. Departamento de Medicina Veterinária, Centro de Ciências Agrárias, Universidade Federal do Espírito Santo, Cx. Postal 16, Alegre, ES 29500-000, Brazil. E-mail: isabella @cca.ufes.br

Twenty-nine stud farms were selected in the Medium Paraíba region of the Rio de Janeiro state, Brazil. After an interview with the person responsible for the animals, faecal samples were collected from mares and analyzed via the EPG technique, faecal cultures, Sedimentation-centrifugo-flotation, and modified Ueno and Baermann techniques. The prevalence of helminths in the mares and in the stud farms was calculated. The stocking rates of pasture, change of horse bedding, absence of pasture rotation, absence of technology in the property, and less frequent treatment of the animals were associated with a greater prevalence of helminths, showing that these variables must be considered in equine control programs. The intensity of the parasitism was also associated with the stocking rate of pasture, absence of dunghill, presence of the animals only in paddocks, lack of technology in the property, less frequent treatment of the animals, and absence of the use of rotation regarding the anthelmintic class.
\end{abstract}

INDEX TERMS: Control practices, management, helminths, treatment, horses.

RESUMO.- [Inquérito sobre práticas de manejo e controle das helmintoses em éguas no Brasil.] Vinte nove haras foram selecionados na região do Médio Paraíba, Estado do Rio de Janeiro, os responsáveis pelos animais entrevistados e amostras fecais de éguas foram coletadas e submetidas às técnicas de OPG, Coprocultura, Sedimentocentrifugo-flutuação, Ueno e Baermann modificadas. A prevalência dos helmintos para as éguas e haras foi calculada. A capacidade de suporte, a troca de cama nas baias, a ausência da rotação do pasto, a ausência do tecnificação na propriedade e menor freqüência do tratamento dos animais foram associadas à prevalência maior dos helmintos, indicando que estas variáveis devem ser consideradas em pro-

\footnotetext{
${ }^{1}$ Received on August 4, 2008.

Accepted for publication on October 24, 2008.

2 Departmento de Medicina Veterinária, Centro de Ciências Agrárias, Universidade Federal do Espírito Santo (UFES), Cx. Postal 16, Alegre, ES 29500-000, Brazil. *Correspsonding author: isabella@cca.ufes.br

${ }^{3}$ Departamento de Parasitologia Animal, Instituto de Veterinária, Universidade Federal Rural do Rio de Janeiro (UFRRJ), Seropédica, RJ 23890-000, Brazil.
}

gramas de controle dos helmintos de eqüinos. A intensidade do parasitismo foi também associado à capacidade de suporte do pasto, à ausência de esterqueira, à presença dos animais somente nos pastos, à ausência do tecnificação na propriedade, à menos freqüência do tratamento e à ausência de uso da rotação da classe anti-helmintica.

TERMOS DE INDEXAÇÃO: Praticas de manejo e controle, helmintos, tratamento, eqüinos.

\section{INTRODUCTION}

Internal parasites are a significant threat to the health of horses. Horses are susceptible to more than 60 internal parasites and may harbor several species of worms at any time. (Stoltenow \& Purdy 2003). Helminths are an important cause of morbidity and mortality in equines, and the prevalence of infection with these parasites is high enough to clinical parasitism (Proudman \& Mattews 2000). In Brazil, in spite of the enormous population of horses, there are few studies on equine helminth control. Also, limited information is available concerning risk factors for worm infection. Factors that are responsible for the development of 
anthelmintic resistance are known; however, other unknown factors may also be important (Lendal et al. 1998). The aim of this paper was to complete a survey on prevalence, management, and control practices of equine helminths and perform an exploratory analysis of the factors associated with its prevalence.

\section{MATERIALS AND METHODS}

Twenty-nine stud farms were selected from registry data of members of the Brazilian Association of Mangalarga Marchador Horse Owners. This data was collected from 78 stud farms in the Medium Paraíba region of the Rio de Janeiro state, Brazil. For the calculation of the sample size of animals, the formula $n=p(1$ p) $(1.96 / ")^{2}$ (Sampaio 1998) was applied. This calculation was performed on the basis of an estimate of prevalence of $61 \%$ $(p=0.61)$ and allowing an error of $5 \%(=0.05)$ and resulted in a sample of 366 animals. The mares was chosen in this study because it was the only category present in all of the visited properties. Between July 2003 and March 2004, two visits to stud farms were carried out. In the first visit, an interview was conducted with the person responsible for the animals. The same interviewer always conducted each interview. A variety of factors were evaluated, including the stocking rates of pasture, the techniques of management in the control of helminths, the frequency of anthelmintic treatment, the most commonly used anthelmintics, the type of formulation, the method of calculation of the anthelmintic dosage, choice of the anthelmintics and the use of anthelmintic class rotation. On the interview day, the appointment for the second visit for collection of the faecal samples was set, in accordance with the anthelmintics control program of each property. The visits for the collection of the faecal samples were conducted during the rainy season in all of the properties, always after a period of at least two months after the last anthelmintic dosage. Then the samples were analyzed by the EPG technique (Gordon \& Whitlock 1939), followed by faecal cultures (Roberts \& O'Sullivan 1950), Sedimental-centrifugalflotation (Martins et al. 2003) and the modified Ueno (Ueno \& Gonçalves 1988) and Baermann (Andresen \& Walters 1973) methods for the identification of the helminths. The data collected through the interviews and the results of the faecal examinations were included into the EPI INFO 2002 Program (CDC 2003). For the analysis, the parasitism intensity, age category of mares, physiological category, and frequency of worming were categorized. The parasitism intensity was categorized on the basis of the number of eggs per gram of faeces (EPG) of the animals, with an upper boundary value of 200 in accordance with Mercier et al. (2001). With the results recorded in the parasitological examination, the prevalence of the helminths in the examined mares and stud farms was calculated, as well as the prevalence of the infective larvae of nematodes in the faecal cultures (Pereira 1995). The associations between the variables were evaluated by the chi-square test $\left(\chi^{2}\right)$, and when necessary the Yates correction and accurate Fisher were used and for the accurate Fisher, with aid of the EPI INFO 2002 program. P values less than 0.05 were considered significant.

\section{RESULTS AND DISCUSSION}

In the present study, 340 animals (96.0\%) were parasitized by at least one species of helminth. The prevalence of helminths in Mangalarga Marchador mares and stud farms is shown in Table 1. These results disagree with those
Table 1. Prevalence of helminths in Mangalarga Marchador mares and stud farms in Rio de Janeiro State, Brazil, between July 2003 and March 2004

\begin{tabular}{lcc}
\hline \multicolumn{1}{c}{ Helminths } & Mares (N=366) & Stud Farms (N=28) \\
\hline Strongyloidea & $94,6 \%$ & $96,4 \%$ \\
Anoplocephalidae & $13 \%$ & $67,8 \%$ \\
Oxyuris equi & $14,1 \%$ & $50 \%$ \\
Parascaris equorum & $7,9 \%$ & $57,1 \%$ \\
Dictyocaulus arnfieldi & $4,8 \%$ & $39,3 \%$ \\
Strongyloides westeri & $2,5 \%$ & $32,1 \%$ \\
Habronema spp & $3,3 \%$ & $25 \%$
\end{tabular}

Sotiraki et al. (1997) in Greece, in which 300 faecal samples of equines of race and traction yielded $62.4 \%$ positive results, with $42.5 \%$ for strongyles, $45.6 \%$ for small strongyles, $0.4 \%$ for Anoplocephala perfoliata, 1.7\% for Parascaris equorum, 4.1\% for Oxyuris equi, 2.2\% for Strongyloides westeri, and $0.9 \%$ for Dictyocaulus arnfieldi. The data from this study also disagree with that of Amhed et al. (1996), who found a positive rate of $65.5 \%$ in a study of equines carried out in Nigeria; $43.2 \%$ had eggs of strongyles, $35.6 \%$ had S. westeri, $1.6 \%$ had $D$. arnfieldi, and $15.6 \%$ had $P$. equorum. The differences observed may be attributed to differences in climate, breed, diagnostic techniques, sample size, and sample technique. Most studies use the McMaster technique for the faecal exams. In this study, however, when the Martins et al. technique (2003) was applied, more positive results were found, because the sedimentation-centrifugo-flotation technique concentrated more eggs. In Brazil, studies reported by Mundim et al. (2000) registered a prevalence of $4 \%$ for $O$. equi but $92.57 \%$ for strongyles, $5.14 \%$ for $S$. westeri, and $9.71 \%$ for $P$. equorum in equines of 30 days to 15 years of age, which was in agreement with the results from this study. Other results totally agree with those of the present study, such as those of Madeira (1985), who found $89 \%$ with strongyle eggs, $2 \%$ with $S$. westeri, and $6 \%$ with $P$. equorum in animals of different age categories.

In the faecal cultures, larvae of the following species were identified: Trichostrongylus axei, Strongylus vulgaris, Gyalocephalus capitatus, $S$. edentatus, S. equinus, and the cyathostomes, with a prevalence in stud farms of $14.3,10.7$, $7.1,7.1,3.6$, and $89.8 \%$, respectively. The present results relating to cyathostomes were similar to those of most of the other studies, including Sartori-Filho et al. (1993) and Mundim et al. (2000), who affirmed that cyathostomes represent the majority of the larvae in the cultures (Rates of other studies are as follows: Madeira (1985) 85\%, Fusé et al. (2002) 85\%, Rodrigues et al. (1995) 95\%, Herd et al. (1985) 95-100\%). Results reported by Sotiraki et al. (1997) showed only $45.6 \%$ prevalence for cyathostomes. Other results of faecal cultures were different, as Fusé et al. (2002) found prevalence rates for Trichostrongylus axei of $3 \%$, Strongylus vulgaris of $2 \%$, S. edentatus of $2 \%$, and Triodontophorus of $8 \%$, and SartoriFilho et al. (1993) found values of $0.5-10 \%$ for S. vulgaris, $0.5-3 \%$ for $S$. edentatus, and $0-3.9 \%$ for $T$. axei.

The EPG averages ranged from 0 to 2350. Stud farm no.14, with an average of 908.70 for 23 examined mares and 2350 EPG in one of the mares, was a property with 
high rates, and the animals were treated with ivermectin, with the last treatment being carried out 2 months before the collection. Others properties, such as stud farms number $19,20,21,22$, and 26, had high averages of helminthes for the anthelmintic used. This fact could be a result of the indiscriminate use of the ivermectin, which was verified by the respondents. This can cause anthelmintic resistance, mainly because none of the owners used faecal examinations to evaluate the anthelmintic efficacy. Almeida et al. (2004) affirmed that $50 \%$ of adults and $54.6 \%$ of the young animals of the Santa Maria Jockey Club had presented with helminths when treated at intervals of 30 and 60 days, and in $44.4 \%$ of the times the treatments were done with ivermectin. Few articles have commented on EPG averages; however, Madeira (1985) found averages of 608 for breastfeeding mares, 822 for empty mares, and 459 for pregnant mares during 3 years of monthly collections. Luiz et al. (1999) found a 500 EPG average, with a range of 50 to 2350. All of the articles reported, as well as the present work, report averages above 500 , and according to Uhlinger (1993), counts above 500 EPG the animals could be contaminating the environment for the other members of the herd, and high counts (higher than 1000 in adult animals) suggest that health performance and immune status should be evaluated. It should be noted that there is no fecal egg count limit for treatment, but the breeding must be monitored monthly through faecal examinations to elaborate an ideal control program. A large amount of data has suggested a limit of EPG for the treatment of the animals, and Mercier et al. (2001) indicated that values of 100 to 300 EPG may be a reasonable goal. In accordance with the observations of some authors, in this study, symptoms generally only appeared in severe infections (EPG above 1000 in adult animals); however, there could be some amount of individual variation and animals without symptoms, but breed animals with high EPG values show damage in development and performance. As there is no correlation between the EPG and the number of parasites in the host, the strategy of control would be to carry out faecal examinations periodically and to treat the animals that have faecal egg counts above 200 , remembering that the boundary-value for EPG must be made on a farm-by-farm basis according to the epidemiology of helminths in each region, or the risk factors for the helminths in each area of study.

Despite the high prevalence of helminths in such a way in the properties as in the animals, the parasitism intensity was low. This observation suggests the presence of subclinical infections that were therefore not perceived by the horse owners, which agrees with the little importance given to worms. However, helminths exist as a source of infections to young animals that affect the performance and appearance of adult animals.

The more frequent questions and answers of the interviews are shown in Table 2.

Table 2. Questions and most frequent answers in interviews of owners of Mangalarga Marchador mares in the state of Rio de Janeiro between July 2003 and March 2004

\begin{tabular}{llc}
\hline \multicolumn{1}{c}{ Questions } & \multicolumn{1}{c}{ Answers } & Frequency \\
\hline Property Management & Manager & $64.3 \%$ \\
Technique Assistance & Veterinarian & $85.7 \%$ \\
Activity time in horse herd & Between 10 and 20 years & $39.3 \%$ \\
Animals borned in properties & More than 50\% & $75 \%$ \\
Most important parasites & Ticks & $78.6 \%$ \\
Period of helminthosis occurence & Do not know & $67.9 \%$ \\
Support capacity of forage & Recommended & $71.4 \%$ \\
Number of mares & More than 20 & $71.5 \%$ \\
Type of feedind & Pasture only & $65.3 \%$ \\
Dunghill & No & $78.6 \%$ \\
Type of environment & Paddocks and bays & $89.3 \%$ \\
Type of bed in bay & Sawdust, sand ou another one & $67.9 \%$ \\
Bed bay change periodically & Yes & $69.7 \%$ \\
Shelter of animals of other farms & No & $71.4 \%$ \\
Pasture consortium with other animals & Ruminants & $32 \%$ \\
Pasture rotation & Yes & $67.9 \%$ \\
Technification of property & No & $60.7 \%$ \\
Faecal egg counts methods & No & $92.8 \%$ \\
Management practice & Tick control & $100 \%$ \\
Frequency of worming & 3 to 4 times a year & $67.9 \%$ \\
Worming used on property & Ivermectin & $85.7 \%$ \\
Calculation of drug dosage & The same for adults and half for youngs & $67.9 \%$ \\
Rotation anthelmintic class & No & $82.1 \%$ \\
Strategy of worming & Based on periodicity & $89.3 \%$ \\
Prescription of worming & Head groom & $60.7 \%$ \\
Period of dosage & The same for all categories & $64.3 \%$ \\
Anthelmintic aplication & Head groom & $75 \%$ \\
Antihelmintic choice & Owner & $57.1 \%$ \\
Difference perception after treatment & Yes & $75 \%$ \\
Under dosing or rejected drugs & No & $89.3 \%$ \\
\hline
\end{tabular}


The type of parasitism considered more important to those interviewed was tick infestation. This suggests that the horse owners visualize the ticks, which does not happen for helminths, because helminthosis is frequently subclinical. That is the reason why owners give little importance to worms. Vidotto (2003), in an article concerning cattle parasitisms, affirmed that the problem of helminthosis is serious; therefore, the animals suffer from an insufficient observation by the owner, but these infections could represent a source of infections in young animals and affect their productivity. Santos-Filho (1999) affirmed that the damage caused by helminth infections is difficult to estimate because about $85 \%$ of the animals present with subclinical illness. Also, helminthosis needs a laboratorial diagnosis, which is never requested by the owner, leading to an underestimation of the importance of the infections. The majority of the interviewed owners answered that they were unaware of the time of higher occurrence of helminths, demonstrating agreement with the reply of the previous item, in which the owners gave little importance to worms.

In relation to the techniques of management utilized, tick control was reported by all of the interviewed owners, $39.3 \%$ of the owners used mixed grazing with ruminants as an alternative to control of helminths and for better grass exploitation, $67.9 \%$ applied pasture rotation, and the majority of the owners removed faeces of bay (89.3\%); however they directly carried them through the grass plot, but only $21.4 \%$ of the stud farms had a dunghill. Some authors also praised the removal of faecal material from the grass (Madeira 1985, Singer et al. 1999, Lloyd et al. 2000, Earle et al. 2002). Earle et al. (2002) in England found that only $24 \%$ of the owners reported that they did not use faecal removal as a form of control of helminths; even so, some owners performed faecal removal daily $(12.8 \%)$. Also in England, Lloyd et al. (2000) found that 48 (32.6\%) owners never collected faeces, while $72(49 \%)$ reported performing this task at least once a week. These results were very different from those found in this study, where none of the interviewed owners reported removing faeces from the pasture, probably because of the laborious practices and expensive costs. These factors were also found to be deterrents by Singer et al. (1999), although they affirmed that the removal of faeces only twice a week is one highly efficient technique to reduce the contamination of pasture.

The anthelmintic most commonly used in the properties was ivermectin, and other researchers have also reported the use of ivermectin as the most frequent drug used in the control of helminths in equines (Lendal et al. 1998, Earle et al. 2002). In Brazil, Almeida et al. (2004) also said that the ivermectin was the anthelmintic most used in the last treatment of the equines of the Santa Maria Jockey, being used in $44.4 \%$ of the animals, while oxibendazol was used in close to $22.2 \%$ doramectin in $11.1 \%$. It is still noticed that the injectable doramectin, which is indicated for cattle, is being used in Brazil by some owners to treat horses. This was reported in the present survey and by Almeida et al. (2004) and Machado et al. (2004). The individual calculation of anthelmintic dosage to each animal was not carried out in the large majority of the properties; only $25 \%$ used the individual average weight, while in the article of Lendal et al. (1998) the interviewed owners affirmed that the most used method of weight estimation was eye measure for the calculation of the anthelmintic dosage, which disagrees with the results of the present study. The recommendation for treatment was more frequently given by the veterinarian of the stud farms. In contrast to the results from the present study, Reinemeyer \& Rohrbach (1990) reported that equine oriented magazines are the most common resource used to make decisions on the parasite control program $(41 \%)$, while the veterinarians were the most common resource in $27 \%$. In the study by Earle et al. (2002), only $42 \%$ of the owners reported receiving advice from veterinarians about control programs. O'Meara \& Mulcahy (2002) reported that are not well clearly if the veterinarians really make significant contributions for the implementation of control programs. The individual responsible for the choice of the drug was, in the majority of cases, the owner. Lloyd et al. (2000) reported in their study that the choice of the anthelmintic is influenced first by articles in magazines and advertisements (32.5\%), followed by veterinarians (31.9\%), and only in the study by Reinemeyer \& Rohrbach (1990) were the veterinarians the major influence of the majority of the interviewed owners (75\%).

The use of appropriated stocking rates of the pasture, the change of horse bedding, the absence of pasture rotation, the absence of technology in the property, and the less frequent treatment of the animals were associated with a greater prevalence of helminths, showing that these variables must be considered in equine control programs. The intensity of the parasitism was associated with the stocking rate, the absence of a dunghill, the presence of the animals only in paddocks, the absence of technology in the property, the lower frequency of treatment, and the absence of the use of rotation of anthelmintic class (Table 3).

Some variables had a greater importance in the determination of higher prevalence as helminths. Thus, the capacity for support of the forage above what is recommended and the higher frequency of treatment determined a greater prevalence $S$. vulgaris; these factor were also associate a higher prevalence of cyathostomes. The mixed grazing with

\section{Table 3. Factors associated with helminth infections of Mangalarga Marchador mares in the state of Rio de Janeiro between July 2003 and March 2004}

\begin{tabular}{lc}
\hline \multicolumn{1}{c}{ Factor } & $\mathrm{p}$ Value \\
\hline Support capacity of forage & $\mathrm{p}<0.01$ \\
Exclusively on pasture & $\mathrm{p}=0.04$ \\
No dunghill & $\mathrm{p}<0.01^{\mathrm{a}}$ \\
Animals in paddocks only & $\mathrm{p}<0.01^{\mathrm{b}}$ \\
Bed bays change & $\mathrm{p}=0.03$ \\
No pasture rotation & $\mathrm{p}=0.02$ \\
No technification & $\mathrm{p}<0.01$ \\
Less frequent worming & $\mathrm{p}=0.03$ \\
No drug class rotation & $\mathrm{p}<0.01^{\mathrm{b}}$
\end{tabular}

a Cyathostomes, b Parasitism intensity. 
ruminants and the lower frequency of treatment were associated with a higher prevalence of $T$. axei and $P$. equorum, respectively. The lower frequency of treatment and change of bed bay were shown to be important variables in the determination of a higher prevalence of $O$. equi.

This study is an exploratory analysis, and other statistical techniques will have to be utilized for confirmation of the real impact of each analyzed variable. There was not evidence to conclude that the number of animals in the property, the shelter of animals from other properties, the mixed grazing with donkeys, the use of faecal examinations, the presence of cutaneous injury, the age category, and the physiological category of the mares are factors that could influence the prevalence of worms or the parasitism intensity. The results of prevalence, management, and control practices applied by the owners of equines in this region showed that the worm control must better be studied. The knowledge of risk factors will simplify the implementation of management and control practices, which are important for monitoring worm control and avoiding the development of anthelmintic resistance. The results of this study will serve as a foundation for future research in the area of helminth control of equines in countries of warm climates, because there is a massive lack of knowledge among herd owners about this subject.

Acknowlegements.- To FAPERJ and CAPES for financial support, and to the horse owners, the laboratory team, and the veterinarians for providing the link with the studs.

\section{REFERENCES}

Almeida G.L., Marin J.B., Gomes R.O., Filho J.O.J. \& Molento M.B. 2004. Freqüência de tratamento antiparasitário e falta de eficácia de helmintos de eqüinos Puro Sangue de Corrida no Jockey Club de Santa Maria, RS Brazil. J. Vet. Parasitol. 13 (Suppl.1):274.

Andresen F.L. \& Walters G.T. 1973. Eficcacy of Bermann technique for recovery of Dictyocaulus viviparus larvae from bovine feces. Am. J. Vet. Res. 34(1):39-40.

Ahmed M.I., Brisibe F. \& Ogbogu V.C. 1996. Age and sex distribution of equine helminthic infections in arid North-Eastern Nigeria. Indian Vet. J. 73(1):16-20.

Center for Disease Control and Prevention 2002. Epi Info. http:// www.cdc.gov/epiinfo/ei2002.htm. Acessed October 1, 2003.

Earle C.G., Kingto H.A. \& Coles G.C. 2002. Helminth control used by trainers of thoroughbreds in England. Vet. Rec. 150(13):405-408.

Fusé L.A., Saumell C.A., Rodriguez H.O. \& Passucci J. 2002. Epidemiologia y control de endoparasitos em potrancas criollas. Revta Med. Vet., Buenos Aires, 83(4):154-158.

Gordon H. Mcl. \& Whitlock H.V. 1939. A new technique for counting nematode eggs in sheep faeces. J. Commonw. Sci. Ind. Organ. 12(1):50-52.

Herd R.P., Willardson K.L. \& Gabel A.A. 1985. Epidemiological approach to the control of horse strongyles. Equine Vet. J. 17(3):202-207.

Lendal S., Larsen M.M., Bjorn H., Craven J., Chriél M. \& Olsen S.N. 1998. A questionnaire survey on nematode control practices on horse farms in Denmark and the existence of risk factors for the development of anthelmintic resistance. Vet. Parasitol. 78(1):49-63.

Lloyd S., Smith J., Connan R.M., Hatcher M.A., Hedges T.R., Humphrey D.J. \& Jones A.C. 2000. Parasite control method used by horse owners: Factors predisposing to the development of anthelmintic resistance in nematodes. Vet. Rec. 146(17):487-492.
Luiz A.P.A., Bellato V., Souza A.P., Silva A.B., Cericatto A.S. \& Zandonadi M. 1999. Prevalência de helmintos em animais de alto padrão zootécnico. Agropec. Catarin. 12(1):39-41.

Machado V.A., Aurnheimer R.C.M., Lisboa P.A.V., Tancredi I.P., Tancredi M.G.F. \& Santos D.C.S. 2004. Eficiência anti-helmíntica da doramectina injetável em eqüinos. Brazil. J. Vet. Parasitol. 13(Suppl.1):272.

Madeira J.F.D. 1985. Observações sobre as helmintoses de eqüinos PSI. Hora Vet. 23(4):39-43.

Martins I.V.F., Verocai G.G., Correia T.R., Mello R.M.P.S., Freitas I.F., Pereira M.J.S. \& Scott F.B. 2003. Validação de uma modificação da técnica de centrifugo-flutuação (Beroza et al. 1986) para o diagnóstico de cestóides em eqüídeos. Brazil. J. Vet. Parasitol. 12(3):99-102.

Mercier P., Chick B., Alves-Branco F. \& White C.R. 2001. Comparative efficacy, persistent effect, and treatment intervals of anthelmintic pastes in naturally infected horses. Vet. Parasitol. 99(1):29-39.

Mundim M.J.S., Mundim A.V., Carvalho F.S.R. \& Faria E.S.M. 2000. Prevalência de ovos de parasitas gastrointestinais em amostras de fezes de equideos de tração em Uberlândia, Minas Gerais, Brasil. Vet. Notícias 6(2):133-137.

O'Meara B. \& Mulcahy G. 2002. A survey of helminth control practices in equine establishments in Ireland. Vet. Parasitol. 109(1-2):101-110.

Pereira M.G. 1995. Epidemiologia: teoria e prática. Ed. Guanabara Koogan, Rio de Janeiro, 596p.

Proudman C.J. \& Matthews J. 2000. Control of intestinal parasites in horses. In Pract. 22(2):90-97.

Reinemeyer C.R. \& Rohrbach B.W. 1990. A survey of equine parasite control in Tennessee. J. Am. Vet. Med. Assoc. 196(5):712-716.

Roberts F.H.S. \& O'Sulivan J.P. 1950. Methods for egg counts and larval cultures for strongyles infesting the gastrointestinal tract of cattle. Aust. Agricult. Res. 1:99-102.

Rodrigues M.L.A. 1989. Sobrevivência de ovos e de larvas infectantes de nematóides (Nematoda, Strongylidae), em eqüinos, nas fezes e na pastagem. Tese de Doutorado, Universidade Federal Rural do Rio de Janeiro.

Sartori-Filho R., Amarante A.E.T. \& Oliveira M.R. 1993. Efeito de medicações anti-helmínticas com ivermectin e febendazole em eqüinos: exames coprológicos e hematológicos. Brazil. J. Vet. Parasitol. 2(1):6164.

Sampaio I.B.M. 1998. Estatística aplicada à experimentação animal. Fundação de Ensino e Pesquisa em Medicina Veterinária e Zootecnia, Belo Horizonte. 221p.

Santos-Filho J.P. 1999. Percepção e realidade de produtores de leite e médicos veterinários da Mesorregião do Agreste do Estado de Pernambuco sobre o controle da verminose bovina. Tese de Doutorado, Universidade Federal Rural do Rio de Janeiro.

Singer J.W., Bobsin N., Bamka W.J. \& Kluchinski D. 1999. Horse pasture management. J. Eq. Vet. Sci. 19(9):540-592.

Sotiraki S.T., Badouvas A.G. \& Himonas C.A. 1997. A survey on the prevalence of internal parasites of equines in Macedonia and Thessalia - Greece. J. Eq. Vet. Sci. 17(10):550-552.

Stoltenow C.L. \& Purdy C.H. 2006. Internal parasites of horses. http:// www.ext.nodak.edu/extpubs/ansci/horse/v543.pdf. Acessed July 7, 2006.

Ueno H. \& Gonçalves P.C. 1988. Manual para diagnóstico das helmintoses de ruminantes. Ed. Japan International Cooperation Agency, Tokyo. $166 \mathrm{p}$.

Uhlinger C.A. 1993. Uses of faecal egg count data in equine practice. Compend. Contin. Educ. Pract. Vet. 15(5):42-748.

Vidotto O. 2005. Complexo Carrapato-Tristeza Parasitária e outras parasitoses de bovinos. http//www.nupel.uem.Br/pos-ppz/complexo08-03.pdf. Acessed March 6, 2005. 